\title{
ANÁLISE DA ESTRUTURA DA PAISAGEM DE UM REMANESCENTE DE FLORESTA COM ARAUCÁRIA, PARANÁ, BRASIL ${ }^{1}$
}

\author{
Gisley Paula Vidolin², Daniela Biondi ${ }^{3}$ e Adilson Wandembruck ${ }^{2}$
}

\begin{abstract}
RESUMO - Este estudo teve como objetivo analisar a estrutura da paisagem da Fazenda Lageado Grande (FLG), área com 3.136,32 ha, localizada em General Carneiro, Palmas e Bituruna, PR, na porção centro-sul do Estado do Paraná. A análise foi baseada no uso de métricas da paisagem do software Fragstats 3.3, mediante a utilização do programa Arc Map 9.2, com cálculos de proporção de áreas de conexão na paisagem. As análises mostraram que a FLG possuía matriz de cobertura do solo predominantemente florestal com espécies nativas; os fragmentos apresentavam, de maneira geral, formas retangulares, ou seja, estavam mais sujeitos aos efeitos de borda; havia redução de mais da metade da área original da Fazenda quando se considera efeito de borda, e os fragmentos de mesma classe estavam próximos uns dos outros, favorecendo a conectividade estrutural da paisagem. Os fragmentos dos ambientes nativos, mesmo que intensamente explorados e alterados, dada a sua continuidade florestal, podem ser considerados áreas de alto valor de conservação da biodiversidade.
\end{abstract}

Palavras-chave: Ecologia da paisagem, Fragmentos e Efeito de borda.

\section{ANALYSIS OF THE LANDSCAPE STRUCTURE IN A REMAINING FRAGMENT OF FOREST WITH ARAUCARIA IN PARANÁ, BRAZIL}

\begin{abstract}
The objective of this study was to analyze the landscape structure of Lageado Grande Farm (LGF), an area of 3,136.32 ha located in General Carneiro, Palmas, State of Tocantins, and Bituruna, in the centersouthern region of the State of Paraná. The analysis was based on the landscape metrics of Fragstats 3.3 software by using Arc Map 9.2 for the calculation of the proportion of the landscape connecting areas. The analysis showed that LGF had a predominantly forest soil cover matrix with native species; overall, the fragments were rectangular, that is, they were more subjected to border effects; there was a reduction of more than half of the original area of the farm, when border effect is considered, and the same class fragments were close to each other, favoring the structural connection of the landscape. The native forest fragments, even extensively and exploited, because of its forest continuity, can be considered areas of high value for biodiversity preservation.
\end{abstract}

Keywords:Landscape ecology, Fragments and Border effect.

\section{INTRODUÇÃO}

Vários índices de paisagem foram desenvolvidos com a finalidade de descrever quantitativamente os padrões e estrutura da paisagem (FORMAN; GODRON, 1986; TURNER; GARDNER, 1990; MCGARIGAL; MARKS, 1995) que, segundo Carrão et al. (2001), recebem hoje cada vez mais atenção, uma vez que auxiliam no processo de compreensão da estrutura complexa da paisagem e na forma como esta influencia determinadas relações ecológicas. De acordo com Turner (1989), os métodos quantitativos são importantes e necessários para a análise da estrutura espacial da paisagem, especialmente para estabelecer as relações entre os padrões que ocorrem na paisagem com uma função ecológica específica. Nesse sentido, muitas métricas têm sido desenvolvidas para descrever padrões espaciais,

\footnotetext{
${ }^{1}$ Recebido em 05.03.2009 e aceito para publicação em 14.04.2011.

${ }^{2}$ Bio Situ Projetos e Estudos Ambientais Ltda. E-mail: <paula@biositu.com.br> e <adilson@biositu.com.br>.

${ }^{3}$ Departamento de Ciências Florestais da Universidade Federal do Paraná, PR, Brasil. E-mail: <dbiondi@ufpr.br>.
} 
a partir de produtos temáticos obtidos através do uso integrado das ferramentas de sensoriamento remoto e geoprocessamento. Essas ferramentas são importantes para a tomada de decisões, tanto em relação ao ambiente natural quanto nas políticas rurais, como agrícolas e florestais (CARRÃO et al., 2001).

O software Fragstats, difundido a partir do ano de 1993 e de distribuição gratuita pela internet, caracteriza-se como importante ferramenta na área de Ecologia de Paisagem, pois disponibiliza inúmeras métricas interpretadas eimplementadas em linguagem computacional (VOLATÃO, 1998). Analisa também índices para fragmentos que compõem a matriz; para as classes de uso e cobertura do solo; e finalmente para a análise da paisagem como um todo (MCGARIGAL; MARKS, 1995). Para cada um desses grupos podem ser calculadas métricas de área, de forma, de borda, de área núcleo, de proximidade e isolamento, de contraste, de contágio e diversidade (MCGARIGAL; MARKS, 1995; COUTO, 2004).

As métricas de área quantificam a composição da paisagem e fornecem a respeito dela informações importantes sobre a dinâmica de populações vegetais e animais (VOLATÃO, 1998). De acordo com Harris (1984), qualquer diminuição em área de um fragmento florestal pode reduzir exponencialmente o número de espécies e afetar a dinâmica de populações de plantas e animais, podendo comprometer a regeneração natural das espécies e, por sua vez, a sustentabilidade do ecossistema. Forman et al. (1976) e Saunders et al. (1991) afirmaram que a riqueza das espécies diminui em uma área à medida que esta fica menor do que as áreas mínimas necessárias para a sobrevivência das populações. Essa área mínima varia em função da espécie considerada e é determinada pelo tamanho do território de um indivíduo (ou de um grupo de indivíduos, em função do comportamento social da espécie) e pelo número mínimo de indivíduos de uma população geneticamente viável (ROSTALTD, 1991). Outro fator relacionado ao tamanho do fragmento e que condiciona a distribuição das espécies é que o tamanho da área interfere na disponibilidade de recursos que, à medida que a área diminui, acarreta também redução nos recursos e, por consequência, intensificação das competições intra e interespecíficas (SEAGLE, 1986).

As métricas de forma são responsáveis pela configuração da paisagem. Segundo Forman (1995), diferentes formas de fragmentos podem ser encontradas na paisagem desde as curvilíneas, compactas ou alongadas até as arredondadas. O ideal, no entanto, é que elas sejam o mais próximo possível da forma circular, pois esse formato minimiza a relação borda-área, cujo centro se encontra mais distante das bordas do que qualquer outra forma, especialmente as alongadas (PRIMACK; RODRIGUES, 2001). Assim, o principal aspecto da forma do fragmento é a sua relação com o efeito de borda (VOLATÃO, 1998).

As características da borda podem afetar os organismos do fragmento, fazendo que eles a evitem, dadas as alterações nas condições bióticas e abióticas. Entre as alterações abióticas estão pronunciados efeitos sobre o microclima, como aumento da temperatura, redução da umidade, aumento da luminosidade, aumento da exposição aos ventos e estresse hídrico. No entanto, espécies oportunistas podem beneficiar-se dessas condições e aumentar a sua densidade nessas áreas, passando a ser elemento de perturbação para a estrutura da comunidade (MURCIA, 1995). Nesse caso, as bordas passam a funcionar como "hábitat armadilha", onde são intensificados, por exemplo, a predação e parasitismo de ninhos e recém-nascidos, acarretando em um sucesso reprodutivo relativamente baixo (METZGER, 1999).

As métricas de área-núcleo ou central ou, ainda, core são consideradas medidas da qualidade de hábitats, uma vez que indicam quanto há realmente de área efetiva de um fragmento, após descontar-se o efeito de borda. Na grande maioria dos casos, os fragmentos possuem área suficiente para manter dada espécie animal, porém não possuem área central capaz de permitir a sua manutenção, especialmente se esse animal tratar-se de espécie de interior. As métricas de proximidade e isolamento se baseiam na distância entre vizinhos mais próximos e podem ser aplicadas para os três grupos tratados pelo Fragstats, ou seja, fragmento, classe e paisagem (VOLATÃO, 1998). Essas métricas são importantes, pois indicam, de forma geral, o grau de isolamento da paisagem e, consequentemente, indicam a existência ou necessidade de implantação de elementos de conexão, como os corredores ecológicos e stepping stones (pontos de ligação).

As métricas relacionadas ao contágio e ao contraste também se relacionam ao grau de isolamento. A partir desses índices é possível obter informações acerca da extensão na qual os fragmentos ou classes estão agregados ou dispersos em uma paisagem e quantificar 
a distribuição espacial de um tipo de fragmento ou classe na paisagem. As métricas de diversidade fornecem dados sobre a riqueza, densidade, heterogeneidade e outros aspectos relacionados aos fragmentos na paisagem (VALENTE, 1998).

Mediante o uso dessas métricas, este trabalho teve como objetivo principal a análise da estrutura espacial da Fazenda Lageado Grande, um remanescente da Floresta com Araucária no Estado do Paraná.

\section{MATERIAL E MÉTODOS}

Esta pesquisa foi realizada na Fazenda Lageado Grande (FLG), propriedade tipicamente florestal, com produção de madeira proveniente de plantações manejadas e de produtos não madeiráveis da floresta, como a extração das folhas de erva-mate (Ilex paraguariensis) (LIMA et al., 2004). Está localizada nos Municípios de General Carneiro e Palmas (PR), com as coordenadas geográficas $26^{\circ} 18$ '11.75”' de latitude Sul e 513'58.94'” de longitude Oeste (Figura 1).

A Fazenda de 3.136,32 ha está inserida na bacia do rio Iguaçu, microbacia do rio Iratim, que dá ao relevo característica fortemente ondulada (CASTELLA;
BRITEZ, 2004). Devido à altitude, ocorrem na área as subformações da Floresta Ombrófila Mista Montana (de 400-1000 m s.n.m.), Alto-Montana (acima de 1.000 m s.n.m.) e Aluvial (nos terraços antigos ao longo dos rios) (VELOSO et al., 1991). O clima é classificado como “subtropical úmido mesotérmico” ( $\mathrm{Cfb}$ ), caracterizado por verão fresco e inverno rigoroso com geadas severas e frequentes, concentradas entre os meses de março e setembro. Não apresenta estação seca característica, com temperaturas médias nos meses mais quentes inferiores a $22^{\circ} \mathrm{C}$ e nos meses mais frios com médias abaixo de $18^{\circ} \mathrm{C}$. O regime de chuvas é irregular, com diminuição no período de inverno e maior intensidade no verão. A precipitação média anual é de 1.500 mm (SMART WOOD PROGRAM, 2002).

O rio Iratim, que apresenta variação de largura entre 10 e $50 \mathrm{~m}$ e estende-se por cerca de $20 \mathrm{~km}$ na propriedade, é o principal rio da área. Esse rio subdivide a propriedade em três porções. A porção Norte, caracterizada integralmente por floresta com predomínio de araucária e manchas de várzeas, que constitui a Reserva Legal da propriedade, com 716,32 ha. As porções Central e Sul da referida área são constituídas por um mosaico paisagístico de reflorestamento com pinus

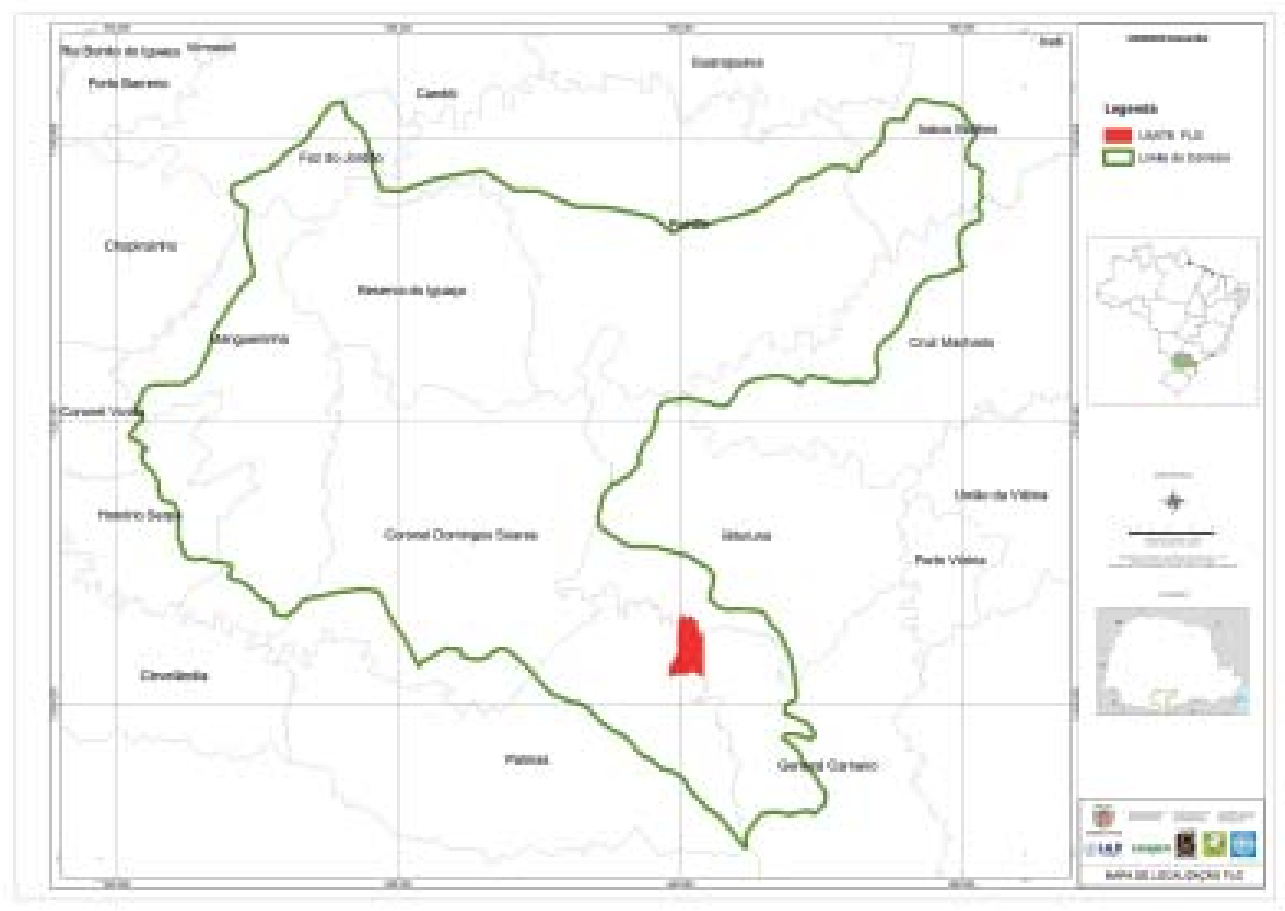

Figura 1 - Mapa de localização da Fazenda Lageado Grande, Paraná, Brasil. Figure 1 - Location map of Lageado Grande Farm, Paraná State, Brazil. 
(Pinus spp.), floresta com predomínio de folhosas, floresta com predomínio de pinheiro e várzeas. Nessas duas porções se concentra a grande maioria das atividades de exploração florestal.

Como é uma área tipicamente florestal, as principais atividades desenvolvidas são: a produção de madeira proveniente de plantações manejadas de pinus e de produtos não madeiráveis da floresta, como a extração das folhas de erva-mate (Ilex paraguariensis) (LIMA et al., 2004). Um dos principais problemas da área são a integridade florística e a estrutural da sua cobertura vegetacional, têm exploração seletiva a que foi submetida no passado e encontra-se seriamente comprometida. Além disso, seu entorno é caracterizado por grandes áreas reflorestadas com pinus, agricultura e pecuária (em baixa escala), faxinal e assentamento rural, que geram diferentes graus de impactos sobre as espécies animais, sobretudo a caça e a descaracterização de hábitats.

\subsection{Mapa de uso e cobertura do solo}

A elaboração do mapa de uso e cobertura do solo da FLG foi feita por meio de interpretação da carta imagem de satélite da área (sensor Ikonos II de 2003, com resolução espacial de 4me escala de 1/10.000), utilizando-se o programa ArcGis versão 9.2. Foram identificadas sete classes principais de uso e cobertura do solo (Figura 2), sendo elas:

a) Floresta com Predomínio de Folhosas (FPF) - Abrange áreas de floresta nativa, em diferentes estágios sucessionais, com dossel contínuo dominado por espécies folhosas. Em algumas áreas, ocorre associação com pinheiros esparsos.

b) Floresta com Predomínio de Pinheiro (FPP) - Abrange áreas de floresta nativa, em diferentes estágios de regeneração, com dossel contínuo dominado pelo pinheiro-do-paraná (Araucaria angustifolia).

c) Várzea (VAZ) - Abrange áreas de vegetação herbácea sobre abaciados hidromórficos, e em algumas áreas ocorre associação com espécies folhosas.

d) Vegetação Secundária (VGS) - Área advinda do abandono do uso do solo, dominada por bracatinga (Mimosa scabrella) e, ou, vassourinhas (Baccharis spp.). Encontra-se em estágio sucessional inicial a médio.

Revista Árvore, Viçosa-MG, v.35, n.3, p.515-525, 2011 e) Vegetação Ciliar (VGC), considerando-se apenas o rio Iratim - Abrange áreas de vegetação localizadas às margens dos cursos d'água. A largura das faixas ciliares foi definida de acordo com o artigo $2^{\circ}$ do Código Florestal e está diretamente relacionada com a largura do curso d’água. Na área de estudo, o rio Iratim apresenta variação de largura entre 10 e $50 \mathrm{~m}$, que corresponde a faixas de floresta ciliar de $50 \mathrm{~m}$ em cada margem. Assim, considerou-se nas análises uma faixa de $50 \mathrm{~m}$ para cada margem.

f) Plantio com Exóticas/Reflorestamento (REF) - Áreas ocupadas com plantios de pinus Pinus spp., para fins industriais.

g) Área de Influência Antrópica (AIA) - Área industrial, solo exposto, cascalheira e estradas.

\subsection{Uso de métricas para análise espacial da paisagem}

Foi utilizado o software Fragstats 3.3 para as métricas de classes e de paisagem, sendo os índices quantificados, de acordo com Volatão (1998), os seguintes:

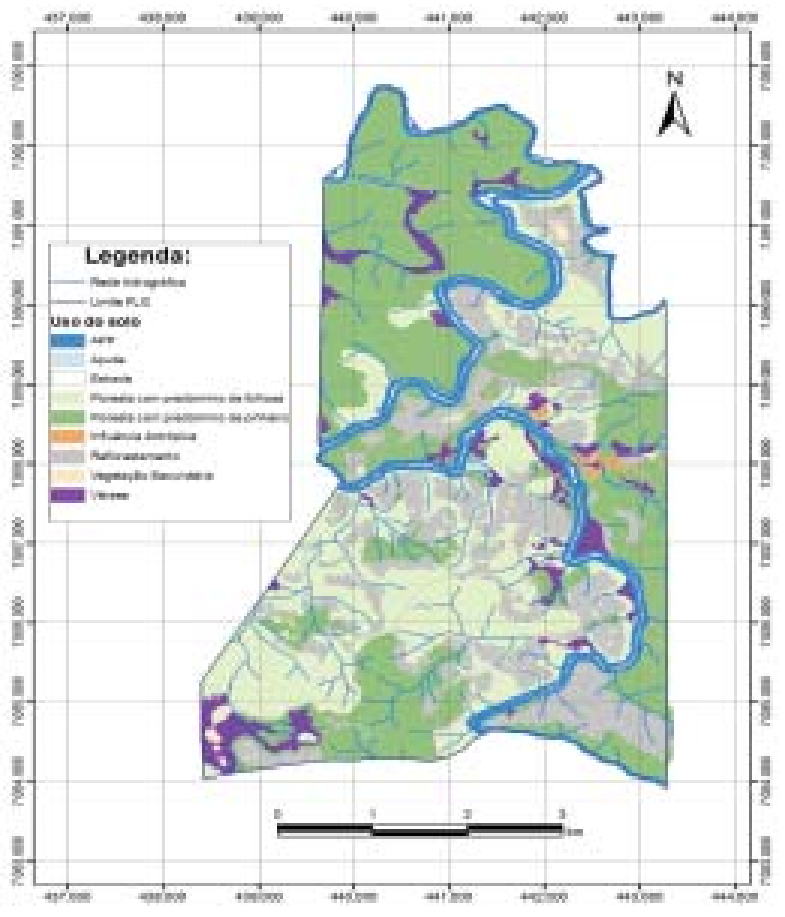

Figura 2 - Mapa das classes de uso do solo (tipos de hábitats) na Fazenda Lageado Grande, Paraná, Brasil.

Figure 2 - Land use class map (types of habitats) in Lageado Grande Farm, Paraná, Brazil. 
A - Métricas de área - Quantificam a composição da paisagem e fornecem sobre ela informações importantes sobre a dinâmica de populações vegetais e animais, e o tamanho de área condiciona a distribuição das espécies e interfere na disponibilidade de recursos. As métricas de área analisadas foram:

a) AREA (área) - Área do fragmento em hectares.

b) CA (área da classe) - Área de todos os fragmentos da classe em há.

c) \%LAND (percentagem da paisagem) - Percentagem de ocupação de fragmentos de mesma classe na paisagem.

d) NP - Número de fragmentos da classe existentes na paisagem.

B - Métricas de forma - São responsáveis pela configuração da paisagem e seu principal aspecto é a sua relação com o efeito de borda que altera as condições bióticas e abióticas dos fragmentos e das espécies ali ocorrentes. As métricas de forma analisadas foram: SHAPE (índice de forma) - mede a complexidade da forma comparada a um círculo (versão vetorial) ou a um quadrado (versão matricial). Para a versão vetorial, no caso do círculo, teria o melhor valor quando SHAPE $=0,88$. Para a versão matricial, que leva em conta os cantos dos pixels e presume os quadrados, os melhores valores são aqueles próximos a SHAPE $=1.13$; o menor valor, desse modo, é SHAPE = 1 para o quadrado. Quanto mais recortado e com menos área, maior o valor desse índice.

C - Métricas de área central (“core”) - É considerada medida da qualidade de hábitat, uma vez que indica quanto existe realmente de área efetiva de um fragmento, após descontar-se o efeito de borda. São elas:

a) TCA (área central total) - Soma das áreas centrais de todas as classes em há.

b) CAI (índice de áreas centrais) - Porcentagem de área central de cada fragmento.

c) C\%LAND (percentual de área central (“core”) na paisagem) - Percentual de áreas centrais (excluídas as bordas de 30 m) em relação à área total da paisagem.

D - Métricas de contágio e agregação:

a) IJI (índice de dispersão e justaposição) - Fornece informações sobre o grau de agregação dos fragmentos componentes das classes na paisagem.
Considera a adjacência de feições dos fragmentos de classe. Varia de 0 a $100 \%$. Valores próximos de 0 indicam que o fragmento não tem contato com outro de sua classe, e valores próximos de 100 indicam entre fragmentos de mesma classe.

b) CLUMPY (índice de agregação) - Fornecem informações acerca da extensão na qual os fragmentos ou classes estão agregados ou dispersos na paisagem, permitindo inferir sobre o isolamento das classes. CLUMPY varia de 0 a 1 , e os valores próximos de 0 indicam que os fragmentos da classe estão distribuídos aleatoriamente na paisagem, ou seja, há maior desagregação entre eles. CLUMPY aumenta à medida que os fragmentos da classe vão-se agregando e estão próximos entre si, sendo os valores próximos de 1 indicadores de agregação entre eles.

c) PLADJ (índice de agregação) - Idem a CLUMPY, porém utilizado para cálculo de métricas da paisagem como um todo.

Além dessas métricas, mediante a utilização do programa Arc Map versão 9.2, foi calculada, ainda, a proporção de áreas de conexão na paisagem (CON).

Análises similares, utilizando algumas das métricas consideradas neste trabalho, foram de acordo com Ferraz e Vettorazzi (2003), que também empregaram o Fragstats 3.3 para identificar áreas de recomposição florestal em uma paisagem manejada.

\section{RESULTADOS E DISCUSSÃO}

A FLG (Fazenda Lageado Grande), considerando-se toda a sua superfície, possui 3.136,32 ha, constituídos por 36,02\% de floresta com predomínio de pinheiro e 24,96\% por floresta com predomínio de folhosas, sendo caracterizada, dessa forma, por uma matriz de cobertura do solo predominantemente florestal com espécies nativas. Outras classes de cobertura na Fazenda são áreas de plantio com espécies exóticas (15,63\%), áreas de influência antrópica - estradas, divisas e a vila de moradores (10,71\%), vegetação ciliar do rio Iratim (7,06\%) e em menor proporção as várzeas (4,31\%), áreas de vegetação secundária em estágios inicial e médio de sucessão ecológica e água (açudes e rio Iratim, propriamente dito), com menos de $1 \%$. O tamanho de área das classes (CA) e a porcentagem de ocupação das classes na paisagem (PLAND) podem ser visualizados na Tabela 1 .

Revista Árvore, Viçosa-MG, v.35, n.3, p.515-525, 2011 
Tabela 1 - Área das classes (CA) e a porcentagem de ocupação das classes na paisagem (PLAND) da FLG.

Table 1 - Class areas (CA) and percentage of occupation of the classes in the landscape (PLAND) of LGF.

\begin{tabular}{ccc}
\hline Hábitat & CA (ha) & PLAND (\%) \\
\hline FPP & $1.129,78$ & 36,02 \\
FPF & 783 & 24,97 \\
REF & 490,19 & 15,63 \\
AIA & 338,24 & 10,78 \\
VGC (Rio Iratim) & 221,51 & 7,06 \\
VAZ & 135,25 & 4,31 \\
Água & 26,64 & 0,85 \\
VGS & 11,71 & 0,37 \\
\hline Total & $3.136,32$ & 100,00 \\
\hline
\end{tabular}

Estradas e divisas, inseridas na classe “AIA” e definidas segundo Marsh (1997), apresentam 880 segmentos de corredores. A área total da grande quantidade de caminhos e acessos existentes no interior da Fazenda é de 323,37 ha (PLAND = 10,31\%). A rede viária da FLG, segundo Freitas e Metzger (2007), é do tipo dendrítica ou ramificada, que suporta atividades de produção madeireira. Com base nesses autores, pode-se afirmar que o tamanho da malha viária na Fazenda Lageado Grande subdivide e fragmenta internamente toda a paisagem, havendo poucos fragmentos de grande extensão sem a presença de estradas. Para Mader (1984) e Forman e Alexander (1998), a barreira formada por estradas, além de fragmentar a paisagem, interrompe o fluxo de algumas espécies, especialmente daqueles de pequeno porte e de interior, e pode causar expressiva alteração nas relações ecológicas entre as espécies que utilizam a borda. Scoss (2002) afirmou que a fragmentação existente internamente nos fragmentos apresenta as mesmas características da fragmentação de paisagens, ou seja, simplificação de hábitats e efeito de borda, entre outros.

O “reflorestamento” é a segunda classe com o maior número de fragmentos ( $\mathrm{NP}=183)$, seguida pela classe “floresta com predomínio de pinheiro" (NP = 75), "floresta com predomínio de folhosas" (NP = 56), "áreas de preservação permanente" ( $N P=41)$ e de "várzeas" $(\mathrm{NP}=32)$. As classes "vegetação secundária” e “áreas de influência antrópica” são as que possuem os menores números de fragmentos ( $\mathrm{NP}=18 \mathrm{eNP}=7$, respectivamente). A classe “água” (açudes e rio Iratim), por sua vez, em virtude de ser ambiente aquático não foi avaliada quanto à fragmentação.

Como há grande variação na porcentagem de ocupação e no tamanho dos fragmentos existentes para cada tipo de hábitat e para melhor avaliar a estrutura da paisagem, as Tabelas 2 e 3 apresentam a distribuição dos fragmentos em classes de tamanho de área, a área (ha) e a porcentagem ocupada pelos hábitats na paisagem da FLG, conforme classes de tamanho dos fragmentos. A análise por classes de tamanho dos fragmentos, segundo Valente (2001), é um bom indicativo do grau de fragmentação, por ser função do número de fragmentos e da área total ocupada pelos hábitats.

A FLG, considerando-se todos os tipos de hábitats de forma associada, é caracterizada por 413 fragmentos, dos quais 332 são menores que 5 ha (80,39\%), e apenas seis são superiores a 100 ha $(1,45 \%)$ (Tabela 2). Quando se correlaciona o número de fragmentos por classe de tamanho com a área total ocupada na paisagem, os fragmentos menores que 5 ha representam 15,33\% da área (427,21 ha), enquanto os fragmentos maiores de 100 ha correspondem 34,65\% da paisagem (965,52 ha)

Tabela 2 - Número de fragmentos dos tipos de hábitat por classe de tamanho de área.

Table 2 - Number of fragments of the habitat types per area size class.

\begin{tabular}{|c|c|c|c|c|c|c|c|c|c|}
\hline \multirow[t]{2}{*}{ Classe (ha) } & \multicolumn{7}{|c|}{ Hábitat } & \multirow[t]{2}{*}{ Total } & \multirow{2}{*}{$\begin{array}{c}\text { \% de Ocupação } \\
\text { na Paisagem }\end{array}$} \\
\hline & VAZ & VGC & FPP & FPF & REF & VGS & AIA & & \\
\hline$<5$ & 26 & 33 & 50 & 42 & 157 & 18 & 6 & 332 & 80,39 \\
\hline $5-10$ & 3 & 1 & 7 & 1 & 22 & 0 & 1 & 35 & 8,47 \\
\hline $10-20$ & 1 & 2 & 5 & 2 & 4 & 0 & 0 & 14 & 3,39 \\
\hline $20-40$ & 2 & 5 & 5 & 6 & 0 & 0 & 0 & 18 & 4,36 \\
\hline $40-60$ & 0 & 0 & 0 & 0 & 0 & 0 & 0 & 0 & 0,00 \\
\hline $60-80$ & 0 & 0 & 5 & 2 & 0 & 0 & 0 & 7 & 1,69 \\
\hline $80-100$ & 0 & 0 & 1 & 0 & 0 & 0 & 0 & 1 & 0,24 \\
\hline$>100$ & 0 & 0 & 3 & 3 & 0 & 0 & 0 & 6 & 1,45 \\
\hline Total & 32 & 41 & 76 & 56 & 183 & 18 & 7 & 413 & 100 \\
\hline
\end{tabular}

Revista Árvore, Viçosa-MG, v.35, n.3, p.515-525, 2011 
Tabela 3 - Área e porcentagem ocupada pelos hábitats na paisagem da FLG, conforme classes de tamanho dos fragmentos. Table 3 - Area and percentage occupied by the habitats in the landscape of LGF according to fragment size class.

\begin{tabular}{|c|c|c|c|c|c|c|c|c|c|}
\hline \multirow[t]{2}{*}{ Classe (ha) } & \multicolumn{7}{|c|}{$\begin{array}{l}\text { Área (ha) Ocupada na Paisagem da FLG por Hábitats, } \\
\text { Conforme Classes de Tamanho dos Fragmentos }\end{array}$} & \multirow[t]{2}{*}{ Total } & \multirow[t]{2}{*}{$\begin{array}{l}\text { \% de Ocupação } \\
\text { na Paisagem }\end{array}$} \\
\hline & VAZ & VGC & FPP & FPF & REF & VGS & AIA & & \\
\hline$<5$ & 51,83 & 8,13 & 64,11 & 26,20 & 256,68 & 11,71 & 8,55 & 427,21 & 15,33 \\
\hline 5 a 10 & 19,33 & 0 & 56,48 & 5,30 & 147,79 & 0 & 6,32 & 235,22 & 8,44 \\
\hline 10 a 20 & 10,79 & 17,23 & 45,17 & 41,54 & 85,72 & 0 & 0 & 200,45 & 7,19 \\
\hline 20 a 40 & 53,3 & 154,28 & 201,25 & 177,76 & 0 & 0 & 0 & 586,59 & 21,05 \\
\hline 40 a 60 & 0 & 41,87 & 0 & 0 & 0 & 0 & 0 & 41,87 & 1,50 \\
\hline 60 а 80 & 0 & 0 & 0 & 70,12 & 0 & 0 & 0 & 70,12 & 2,52 \\
\hline 80 a 100 & 0 & 0 & 175,29 & 84,04 & 0 & 0 & 0 & 259,33 & 9,31 \\
\hline$>100$ & 0 & 0 & 587,48 & 378,04 & 0 & 0 & 0 & 965,52 & 34,65 \\
\hline
\end{tabular}

(Tabela 3). Esses valores indicam que o alto percentual de fragmentos de tamanho reduzido implica que estes estão mais sujeitos ao efeito de borda e que 427,21 ha da Fazenda podem estar sujeitos a serem constituídos por hábitats com características de borda (RODRIGUES, 1993; BENDER et al., 1998). Já os fragmentos maiores que 100 ha têm maior influência por representarem a maior proporção de área ocupada na paisagem. Além disso, são capazes de manter sua estrutura interna e a estabilidade da estrutura florestal da paisagem em que estão inseridos (VALENTE, 2001).

Com relação à forma, os índices obtidos para “vegetação ciliar”, “reflorestamento” e "influência antrópica” indicam que essas classes são as que se apresentam mais recortadas e com fragmentos de formas irregulares e alongadas (não circular). Esse formato mais irregular se deve, no caso da "vegetação ciliar", à configuração espacial do rio Iratim, que corta a Fazenda ponta a ponta, formando inúmeras reentrâncias na paisagem ao longo do seu percurso. No caso das classes "reflorestamento" e "influência antrópica”, as formas irregulares se devem à configuração da densa malha viária, implantada para atender às atividades de plantio e colheita de pinus na área.

As classes onde o SHAPE se aproxima da forma circular se referem às classes "vegetação secundária”, “floresta com predomínio de folhosa”, “várzea” e “floresta com predomínio de pinheiro”, sendo esta última a que possui maior área ocupada na paisagem, ou seja, é a matriz (Tabela 4). O formato dos fragmentos de várzeas está condicionado às faixas ocupadas pelo solo hidromórfico. A classe "vegetação secundária”, embora possua melhor forma, é a que apresenta menor PLAND.
A média do índice de forma obtido para a paisagem como um todo foi de um SHAPE igual a 1,47, indicando que os fragmentos existentes na FLG apresentam, de maneira geral, formas mais próximas a um retângulo com lados L e 10 L e SHAPE = 1,74 (VOLATÃO, 1998). Forman e Godron (1986), Forman (1995) e Grise (2008) citaram que valores de índices de forma de fragmentos próximos a 1,0 representam formas mais circulares $(1,0$ representa a forma de um círculo perfeito), enquanto valores como 3 e 4 correspondem a formas bastante irregulares. Os fragmentos com forma irregular estão mais suscetíveis a apresentar maior efeito de borda, principalmente aqueles de menor área, em virtude da sua maior interação com a matriz.

Com o aumento do efeito de borda, tem-se, proporcionalmente, a diminuição da área nuclear desses fragmentos, o que em curto, médio ou longo espaços de tempo irá influenciar na qualidade da estrutura desses ecossistemas (VALENTE, 2001). Martins et al. (2002) também relataram que fragmentos com tendências longilíneas, ou seja, com valores de forma inferiores a 1, apresentam alta razão borda/

Tabela 4 - Valores do "SHAPE” (índice de forma) das classes na paisagem da FLG.

Table 4 -SHAPE values (shape index) of the classes in the LGF landscape.

\begin{tabular}{lc}
\hline Classes & SHAPE - Índice de forma \\
\hline VGC & 3,68 \\
REF & 2,23 \\
AIA & 1,97 \\
FPP & 1,88 \\
VAZ & 1,78 \\
FPF & 1,74 \\
VGS & 1,36 \\
\hline
\end{tabular}

Revista Árvore, Viçosa-MG, v.35, n.3, p.515-525, 2011 
interior e, quanto mais alongada, maior a região de área exposta a efeitos ambientais, resultantes de ações antrópicas.

No caso da FLG, pelo fato de a matriz ser constituída pela "floresta com predomínio de pinheiro" e "floresta com predomínio de folhosas”, possivelmente o efeito de borda não seja tão pronunciado. Apesar disso (já que a grande maioria das manchas está circundada pela malha viária), foi considerado um efeito de borda hipotético de 30 m, onde praticamente todas as classes tiveram redução demais de 50\% de suaárea ao se excluir a faixa correspondente ao efeito de borda considerado (Tabela 5).

Ressalta-se que nesta análise foi desconsiderada a classe “área de influência antrópica”, já que o efeito de borda não se aplica aos tipos de ambientes que a constituem (estradas, aceiros e vila). No entanto, a análise de efeito de borda versus área-núcleo foi considerada para a classe “várzea”, uma vez que há nítida diferenciação, em termos de composição de espécies e de estrutura da vegetação, entre as porções periféricas e da área central desses hábitats. Somente quando as várzeas são limítrofes da vegetação ciliar é que se observa substituição gradual de espécies vegetais. Quando são limítrofes de áreas de plantio ou, mesmo, de outros hábitats naturais (áreas de florestas com predomínio de pinheiro e de folhosas), as porções periféricas apresentam padrão bastante diferenciado (adensamento de taquaras) daquele encontrado na áreanúcleo (onde ocorrem as espécies características desse ambiente úmido). No caso dos hábitats de vegetação nativa, a faixa de transição com as várzeas também se apresenta bastante descaracterizada, principalmente devido à exploração pretérita de madeira e atual exploração

Tabela 5 - Valores de "TCA" e "CPLAND" considerando o efeito de borda de $30 \mathrm{~m}$ e a redução de área das classes que constituem a paisagem da FLG.

Table 5 - TCA and CPLAND values considering the 30-m border effect and area reduction of the classes that form the LGF landscape.

\begin{tabular}{cccccc}
\hline Hábitat & $\begin{array}{c}\text { CA (ha) } \\
\text { (ha) }\end{array}$ & $\begin{array}{c}\text { TCA } \\
\text { (ha) }\end{array}$ & $\begin{array}{c}\text { CPLAND } \\
\text { (\%) }\end{array}$ & $\begin{array}{c}\text { Redução de } \\
\text { Área (ha) }\end{array}$ & $\begin{array}{c}\text { Redução } \\
\text { em \% }\end{array}$ \\
\hline VGC & 221,51 & 9,21 & 0,61 & 212,30 & 95,84 \\
VGS & 11,71 & 2,53 & 0,17 & 9,18 & 78,42 \\
VAZ & 135,25 & 46,82 & 3,10 & 88,43 & 65,38 \\
REF & 490,19 & 185,63 & 12,28 & 304,56 & 62,13 \\
FPF & 783 & 486,34 & 32,18 & 296,66 & 37,89 \\
FPP & $1.129,78$ & 773,0093 & 51,16 & 356,77 & 31,58 \\
\hline
\end{tabular}

da erva-mate, com consequente supressão das demais espécies de sub-bosque. Além disso, em alguns casos estradas subdividem as várzeas em duas porções e as submetem à presença de elementos perturbadores nas bordas. Essas observações foram realizadas tanto nas várzeas arbóreas quanto nas herbáceas.

Considerando ainda as análises de efeito de borda hipotético de $30 \mathrm{~m}$ correlacionado com a diminuição da área nuclear dos fragmentos, tem-se que a classe mais comprometida foi a "vegetação ciliar”, com redução de $95,84 \%$, passando de 221,51 ha de área original para apenas 9,21 ha de área-núcleo. Cabe relembrar que a “vegetação ciliar” constitui-se como corredor de hábitat, e alterações na sua qualidade ambiental podem afetar diretamente as possibilidades de deslocamento de espécies animais que utilizam a vegetação ciliar para transitar na paisagem. Outra classe que sofreu redução expressiva é a de "várzea", com redução de 65,38\% de sua área, passando de 135,25 ha para 88,43 ha.

A classe “vegetação secundária” sofreu redução de 78,42\%, passando de uma área originalmente pequena de 11,71 ha para 2,53 ha de área-núcleo. A redução das áreas de vegetação secundária prejudica o avanço do processo sucessional, bem como a sua colonização por espécies animais; consequentemente, processos ecológicos que deveriam ser desempenhados pela fauna, como dispersão e polinização, passam a não ser efetivos para a recuperação desses hábitats.

As classes, mesmo após a exclusão da faixa de $30 \mathrm{~m}$, correspondente ao efeito de borda considerado, que perderam menor porcentagem de sua área original, foram a “floresta com predomínio de folhosas” (37,89\%, passando de uma área original de 783,00 ha para 486,34 ha de área-núcleo) e a "floresta com predomínio de pinheiros” (31,58\%, passando de uma área original de 1.129,78 ha para 773,27 ha de área-núcleo).

Considerando a paisagem como um todo, houve redução de 51,04\% onde a área original, que era constituída por 3.136,32 ha, passou a ser de 1.508,09 ha de área-núcleo.

Na Tabela 6, observa-se o índice de dispersão e justaposição (IJI) que indica a distribuição com que os fragmentos se encontram na paisagem (variam de $0 \%$ a $100 \%$ ). Constatou-se que os fragmentos da classe de "floresta com predomínio de pinheiros" (IJI = 72,95\%) estiveram mais bem distribuídos na paisagem da FLG. Essa distribuição veio seguida pelos fragmentos da 
classe "floresta com predomínio de folhosas" (IJI = $68,10 \%)$. As classes, em que seus fragmentos estão concentrados em determinadas porções da FLG, são: "várzeas" IJI = 54,86\% e "áreas de vegetação ciliar" $\mathrm{IJI}=54,86 \%$.

O índice obtido da métrica de contágio e agregação (CLUMPY, cujos valores variam de 0 a 1 ) indica, de forma geral, que os fragmentos de todas das classes possuem vizinhos semelhantes relativamente próximos. As classes que possuem maior agregação de seus fragmentos são as de “floresta com predomínio de pinheiros” (CLUMPY = 0,89) e "floresta com predomínio de folhosas" (CLUMPY = 0,89), indicando que os fragmentos dessas classes possuem menor isolamento entre si. Da mesma forma, os valores encontrados para as classes de hábitats indicam que os fragmentos desses hábitats estão próximos entre si: para a classe “várzea”, o CLUMPY obtido foi de 0,82 e para a classe "vegetação ciliar”, de 0,73 (Tabela 6).

Os elementos de conexão (CON), constituídos pela vegetação ciliar do rio Iratim e demais corpos d'água existentes na FLG e que representam o segundo tipo de hábitats mais selecionado pelas espécies, perfazem 22,42\% da paisagem da FLG.

Considerando os valores de dispersão e justaposição (IJI = 65,57\%), de contágio e agregação para a paisagem como um todo (PLADJ = 85,31\%), e a proporção de elementos de conexão (CON $=22,42 \%$ ), bem assim que a matriz é florestal com espécies nativas, é possível afirmar que há pseudocontinuidade florestal que favorece o estabelecimento de estruturas de conexão, além de propiciar um mosaico importante para manutenção da flora e fauna locais. Valente (2001) constatou o mesmo padrão estrutural para as sub-bacias da Bacia do Rio Corumbataí, com a exceção de que os fragmentos estavam

Tabela 6 - Valores de "IJI" e "CLUMPY" para as classes de hábitat da FLG.

Table 6 - IJI and CLUMPY values for the habitat classes of $L G F$.

\begin{tabular}{ccc}
\hline Hábitat & IJI (\%) & CLUMPY \\
\hline FPP & 72,95 & 0,89 \\
FPF & 68,09 & 0,89 \\
VGS & 64,88 & 0,71 \\
VAZ & 58,59 & 0,82 \\
VGC (Rio Iratim) & 54,86 & 0,73 \\
REF & 54,44 & 0,81 \\
\hline
\end{tabular}

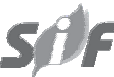

inseridos em uma matriz não florestal, diferentemente da FLG, cuja matriz é predominantemente florestal com espécies nativas. Nesse sentido, os fragmentos com predomínio de pinheiros e de folhosas que possuem área superior a 100 ha, ainda que intensamente explorados e alterados, podem ser considerados áreas de alto valor de conservação da biodiversidade.

Ambientes, no entanto, como as várzeas e a vegetação ciliar do rio Iratim, podem ser considerados em estado crítico, uma vez que: (a) naturalmente a distribuição dos fragmentos desses hábitats é restrita por estar condicionada a características relacionadas ao tipo de solo e ao relevo, ou seja, são escassos e fragmentados; (b) devido à baixa proporção de área que ocupam, pequenas alterações na paisagem poderiam causar impactos severos nesses ambientes e modificar a estrutura espacial da paisagem como um todo, acarretando mudanças bruscas nas respostas ecológicas das espécies ocorrentes na área. Assim, ações de manejo paisagístico voltadas para a manutenção e proteção desses ambientes devem receber atenção especial.

Essa situação, sobretudo nas várzeas, também é encontrada nas propriedades situadas no entorno imediato ou próximas à Fazenda Lageado Grande, em um recorte espacial de $659 \mathrm{~km}^{2}$, situado entre as coordenadas geográficas $26^{\circ} 26^{\prime} 35^{\prime \prime}$ de latitude S e 51 46'10”'de longitude W e $26^{\circ} 12^{\prime} 19$ '” de latitude S e 51 ${ }^{\circ} 24^{\prime} 45^{\prime \prime}$ ' de longitude W. Esse recorte é caracterizado por 56,63\% de fragmentos de floresta nativa, $24,89 \%$ de fragmentos de reflorestamento e $14,72 \%$ por áreas de uso antrópico, ressaltando-se que as várzeas representam apenas 3,16\% da macropaisagem. Os elementos de conexão (vegetação ciliar) representam, nesse caso, 23,26\%. Os fragmentos de floresta nativa, que caracterizam a matriz, são os hábitats que se encontram mais bem distribuídos na paisagem (IJI =75,88\%) e com vizinhos de mesma classe relativamente próximos(CLUMPY=0,75).As várzeas também seencontram mais bem distribuídas (IJI = 67,76\%), porém mais isoladas (CLUMPY = 0,55).

Cabe ressaltar que as várzeas, por serem ecossistemas diversos, funcionam como corredor ecológico e também como local complexo, onde ocorrem espécies de ambiente aquático, terrestre e de adaptação aos dois ambientes (PASCHOAL; CAVASSAN, 1999). Assim, a manutenção dos remanescentes dessa vegetação e a restauração ecológica das que já foram degradadas também são extremamente importantes.

Revista Árvore, Viçosa-MG, v.35, n.3, p.515-525, 2011 


\section{CONCLUSÕES}

Os índices de paisagem considerados, quando analisados em conjunto, permitiram a caracterização da estrutura da paisagem e a avaliação da área, do ponto de vista da preservação e conservação dos hábitats. De acordo com os índices de paisagem calculados, pôde-se constatar que a característica da matriz (predominantemente florestal com espécies nativas), associada à proporção de elementos de conexão, confere à paisagem da FLG, juntamente com as demais propriedades de seu entorno, continuidade florestal ou conexão física dos fragmentos, o que favorece a sua conectividade estrutural.As várzeas representam a classe que se apresenta em estado mais crítico de conservação, sendo, portanto, altamente prioritárias e devem receber tratamento especial no que se refere à adoção de estratégias de conservação e, ou, de manejo da paisagem local.

\section{REFERÊNCIAS}

BENDER, D.J.; CONTRERAS, T.A.; FAHRIG, L. Hábitat loss and population decline: a metaanalysis of patch size effect. Ecology, v.79, n. 2, p.517-533, 1998.

CARRÃO, H.; CAETANO, M.; NEVES, N. LANDIC: cálculo de indicadores de paisagem em ambiente SIG. In: ENCONTRO DE UTILIZADORES DE INFORMAÇÃO GEOGRÁFICA - ESIG, 6, 2001, Oeiras, Portugal. Anais... Lisboa: Associação dos Utilizadores de Sistemas de Informação Geográfica - USIG, 2001.

CAStella, P. R.; BRITEZ, R. M. A Floresta com Araucária no Paraná. Ministério do Meio Ambiente - MMA, Fundação de Pesquisas Florestais do Paraná, Brasília, Brasil, 233 pp. 2004.

COUTO, P. Análise factorial aplicada a métricas da paisagem definidas em Fragstats. Investigação Operacional, vol. 24, p. 109-137, 2004.

FERRAZ, S. F. de B.; VETTORAZZI, C. A. Identificação de áreas para recomposição florestal com base em princípios de Ecologia da Paisagem. Revista Árvore, vol. 27, n. 004, pp. 575-583, 2003.

FORMAN, R. T. T. Land mosaics: The ecology of landscapes and region. New York: Cambridge Press, 1995. 632 p.
FORMAN, R. T. T.; A. E. GALLI; C. F. LECK. Forest size and avian diversity in New Jersey woodlots with some lande use implications. Oecologia, v. 26, p. 18-8, 1976.

FORMAN, R. T. T.; ALEXANDER, L. E. Roads and their major ecological effects. Annual Reviews in Ecology e Systematics, v. 29, p 207-231, 1998.

FORMAN, R. T. T.; GODRON, M. Landscape ecology. USA: J. Wiley, 1986.

FREITAS, S. R.; METZGER, J. P. Relação entre a densidade e a conectividade das estradas e o relevo em uma paisagem da Mata Atlântica (Planalto de Ibiúna, SP). In: Simpósio Brasileiro de Sensoriamento Remoto, XIII. Florianópolis, Brasil. Anais... Florianópolis: INPE, p. 26592664. 2007.

GRISE, M. M. A estrutura da paisagem do mosaico de unidades de conservação do litoral norte do Paraná. Curitiba, 2008, 108 f. Dissertação (Mestrado em Engenharia Florestal) - Universidade Federal do Paraná.

HARRIS, L.D. The fragmented forest: island biogeography theory and the preservation of biotic diversity. Chicago: University of Chicago. 1984. 229 p.

LIMA, E. de C. de; SANQUETTA, C. R.; KIRCHNER, F. F.; FERRETTI, E. R. 2004. Qualidade da paisagem: estudo de caso na Floresta Ombrófila Mista. Revista Floresta, Curitiba, v. 34, n. 1, p. 45-56, 2004.

MADER, H. J. Animal hábitat isolation by roads and agricultural fields. Biological

Conservation, vol. 29, n. 1, p. 81-96, 1984.

MARSH, W. M. Landscape Planning:

Environmental Application. $3^{\text {a }}$ ed., John Willey, New York, 1997, 434 p.

MARTINS, I. C. de M.; SOARES, V. P.; SILVA, E.; BRITES, R. S. Diagnóstico ambiental no contexto da paisagem de fragmentos florestais naturais “ipucas” no município de Lagoa da Confusão, Tocantins. Revista Árvore, vol. 26, n. 3, p. 299-309, 2002. 
MCGARIGAL, K; MARKS, B. J. FRAGSTATS: spatial pattern analysis program for quantifying landscape structure. Portland: Department of Agriculture, Forest Service, Pacific Northwest Research Station. 1995. 122 p.

METZGER, J. P. Estrutura da Paisagem e Fragmentação: análise bibliográfica. In: An. Acad. Bras. Ci., v. 71, n. 3, 1999.

MURCIA, C. Edge effects in fragmented forests: implications for conservation. Tree, vol. 2, p. 58-62, 1995.

PASCHOAL, M. E. S.; CAVASSAN, O. A. Flora arbórea da Mata de Brejo do Ribeirão do Pelintra, Agudos, SP. Naturalia, São Paulo, v. 24, p.171-191, 1999.

PRIMACK, R. B.; RODRIGUES, E. Biologia da Conservação. Londrina: E. Rodrigues. 328 p, 2001.

RODRIGUES, E. Ecologia de fragmentos florestais no gradiente urbano de Londrina - PR. São Carlos, 1993. Dissertação (Mestrado) Universidade de São Paulo, USP-EESC São Carlo.

ROSTALDT, J. Consequences of forest fragmentation for the dynamics of bird population: conceptual issues and the evidence. Biol. J. Linn. Soc., vol, 41, p. 149-163, 1991.

SAUNDERS, D. A.; HOBBS, R. J.; MARGULES, C. R. Biological consequences of ecosystem fragmentation: a review. Conservation Biology, v.5, p.18-32, 1991.

SCOSS, L. M. Impacto de estradas sobre mamíferos terrestres: o caso do Parque Estadual do Rio Doce, Minas Gerais. Minas Gerais, 2002, 97 f. Tese (Magister Scientiae Programa de Pós-Graduação em Ciência Florestal) - Universidade Federal de Viçosa.
SEAGLE, S. W. Generation of species-area curves by a model of animal-hábitat dynamics. In Verner, M. L.; M. L. Morrisson; C. J. Ralph. Wildlife 2000 - Modeling hábitat relationships of terrestrial vertebrates. Madison, The University of Wisconsin. 1986. p. 281-286.

\section{SMART WOOD PROGRAM, Resumo} Público de Certificação de Indústrias Pedro N. Pizzatto Ltda. General Carneiro, Paraná. 2002. 39 p.

TURNER, M.G. Landscape ecology: the effect of pattern on process. Annual Review of Ecology and Systematics, vol. 20, p. 171-197, 1989.

TURNER, M.G.; GARDNER, R. H. Quantitative methods in landscape ecology: the analysis and interpretation of landscape heterogeneity. New York: Springer Verlag, 1990. 536 p.

VALENTE, R. de O. A. Análise da estrutura da paisagem na bacia do Rio

Corumbataí, SP. Piracicaba, 2001, 161 f. Dissertação (Mestrado em Recursos Florestais) Escola Superior de Agricultura "Luiz de Queiroz", Universidade de São Paulo.

VELOSO, H. P.; RANGEL-FILHO, A. L.; LIMA, J. C. Classificação da vegetação brasileira adaptada a um sistema universal. IBGE. Rio de Janeiro. 1991.

VOLATÃO, C. F. S. Trabalho de análise espacial - Métricas do Fragstats. INPE, São José dos Campos. 1998. 